\title{
Evaluation of Screening Strategies for Improving Oral Cancer Mortality: A Cochrane Systematic Review
}

\author{
Omar Kujan, D.D.S., M.Sc.; Anne-Marie Glenny, B.Sc., M.Med.Sc.; John Duxbury, B.D.S., \\ M.Sc., F.D.S.R.C.S. (UK), Ph.D.; Nalin Thakker, B.D.S., M.Sc., F.R.C.Path. (UK), Ph.D.; \\ Philip Sloan, B.D.S., F.D.S.R.C.S. (UK), F.R.C.Path. (UK), Ph.D.
}

Abstract: Worldwide, oral cancer has one of the lowest survival rates. It is well recognized that survival rates are improved if the disease is treated in its early stages. The aim of this study was to assess the effectiveness of screening methods in decreasing the mortality of oral cancer. A systematic review on the effectiveness of oral cancer screening was performed using all publications in MEDLINE, CANCERLIT, EMBASE, and Cochrane CCTR between 1966 and September 2002. The evidence was evaluated using the standardized methodology of the Cochrane Collaboration. The search strategy revealed 1,389 citations. From these, 100 potentially relevant articles were selected for review. However, only one randomized controlled study using visual examination as the method for screening fulfilled the selection criteria. Given the limitation of evidence and the potential methodological weakness in the included study, it is valid to say that there is no evidence to recommend inclusion or exclusion of screening programs for oral cancer using visual examination in the general population. In addition, no robust evidence exists that indicates whether other screening methods including toluidine blue, fluorescence imaging, or brush biopsy are either beneficial or harmful. Further high-quality studies to assess the efficacy and effectiveness of screening are required. Additional investigations aimed at elucidating the natural history of oral cancer and evaluating the effectiveness of prevention and opportunistic screening in highrisk groups are needed. A greater understanding of the genetic basis of oral cancer is an essential prerequisite to the development of molecular markers for screening.

Dr. Kujan is a Ph.D. student, Unit of Oral Pathology, School of Dentistry, University of Manchester; Ms. Glenny is Lecturer, Unit of Research Methods, School of Dentistry, University of Manchester; Dr. Duxbury is Senior Lecturer/Hon. Consultant, Unit of Oral Medicine, School of Dentistry, University of Manchester; Dr. Thakker is Professor, Department of Medical Genetics, School of Medicine, University of Manchester; and Dr. Sloan is Professor and Head of Oral and Maxillofacial Sciences Department, School of Dentistry, University of Manchester. Direct correspondence and requests for reprints to Dr. Omar Kujan, Unit of Oral Pathology, School of Dentistry, University of Manchester, Higher Cambridge Street, Manchester M15 6FH, England; 44(0)161275-8939 phone; 44(0)161-275-6797 fax; omar.kujan@student.manchester.ac.uk.

This article is a modified version of a systematic review titled "Screening Programmes for the Early Detection and Prevention of Oral Cancer” by Kujan O, Glenny AM, Duxbury AJ, Thakker N, Sloan P and published in Issue \#4, 2003 of the Cochrane Library. Copyright Cochrane Library, reproduced with permission.

Key words: screening, oral cancer and precancer, systematic review

Submitted for publication 10/25/04; accepted 11/19/04

$\mathrm{T}$ he term "oral cancer" includes all malignancies arising from the lips, oral cavity, oropharynx, nasopharynx, hypopharynx, and other ill-defined sites within the lip, oral cavity, and pharynx. ${ }^{1}$ It has been estimated that more than 30,000 new cases of oral cancer are diagnosed in the United States each year, with approximately 8,000 associated deaths. ${ }^{2}$ In the United Kingdom in 1999, the number of newly diagnosed cases of oral cancer was 3,268 in males and 1,831 in females, and the num- ber of deaths was approximately $1,600 .^{3}$ Although globally oral cancer represents an incidence of 3 percent (males) and 2 percent (females) of all malignant neoplasms, it has one of the lowest survival rates -50 percent, within a five-year period. ${ }^{4}$ The World Health Organization reported oral cancer as having one of the highest mortality ratios amongst all malignancies. ${ }^{5}$

Unfortunately, most oral cancers lack early signs, ${ }^{6}$ and despite improvements in diagnostic and 
therapeutic modalities, the prognosis of patients with oral malignancies has remained poor. In essence, this poor outcome is related to the majority of patients presenting at an already advanced stage of disease at occurs in a region of the body that is generally accessible to physical examination by the patient, the dentist, and the physician. ${ }^{8}$ As with other types of cancer, the key to decreasing the suffering of patients and increasing their survival rate is early detection. As a result, attention has been drawn to the potentially successful role of cancer screening programs. ${ }^{9}$

The UK Working Group on screening for oral cancer and precancer concluded that the most suitable screening for oral cancer and precancer is a thorough and methodical examination in good lighting of the mucosal surfaces of the oral cavity. ${ }^{10}$ Since 1960, many studies have focused on the important role of toluidine blue dye as an adjunct to the detection of oral cancer. ${ }^{11-13}$ Two emerging advanced technology methods for use in oral cancer screening programs are fluorescent imaging and brush biopsy. ${ }^{14,15}$

The aim of this study was to systematically review the literature relating to the effectiveness of specific screening techniques for oral cancer in asymptomatic individuals with a view to informing current practice. ${ }^{16,17} \mathrm{~A}$ secondary objective was to assess the effectiveness of early stage detection and morbidity. the time of diagnosis. ${ }^{7}$ Moreover, cancer of the mouth

\section{Materials and Methods}

The systematic review followed the guidelines contained in the Cochrane Collaboration. ${ }^{18}$ It synthesizes the evidence qualitatively and then, only where appropriate, uses quantitative methods.

Articles were eligible if they 1) were designed as a randomized control trial (RCT);2) described a program providing screening for the early detection of oral cancer or potentially premalignant oral lesions including the following methods: visual screening, toluidine blue, fluorescence imaging, and/or brush biopsy; and 3) included follow-up of at least three years.

The primary outcome considered in this review is oral cancer-specific mortality. Other outcomes considered include incidence of oral cancer or potentially premalignant oral lesions, mortality at three or more years, stage at diagnosis, harms of screening (including adverse outcomes from false positive or false negative result on initial screen), costs, and quality of life.

Articles relevant to the search strategy were identified from searches of MEDLINE, CANCERLIT, EMBASE, and Cochrane CCRCT (Central) databases for the period 1966 to September 2002. The search strategy used terms for three categories-oral anatomical parts, cancer, and screening methods - and was supplemented with a textword search (Table 1). In addition, hand-searching was performed for the following journals: British Journal of Cancer, British Dental Journal, Cancer, Cancer Research, Community Dental Health, Community Dentistry, and Oral Epidemiology. Non-English papers were included. The bibliographies of included articles and relevant review articles were checked for studies not identified through the electronic databases or hand-searched journals. Authors of identified RCTs, personal contacts, and manufacturers were contacted to identify unpublished or ongoing trials.

All studies meeting the instring of characters before the $\$$ symbol.
Early detection
words that begin with the

Note: The symbol \$ acts as a "wildcard" and matches all words that begin with the

tolonium chloride TOLUIDINES toluidine dye brush biopsy fluorescent imaging prevent\$

tongue\$ or gingiv\$ or

oropharynx or palate or cheek\$

screen\$ clusion criteria underwent validity assessment, data extraction, and statistics evaluation by two 
authors (OK, AMG). The two reviewers undertook the quality assessment of the included trials independently and in duplicate as part of the data extraction process.

The quality of included studies was assessed using four criteria:

1. Randomization and allocation concealment for each trial was coded according to the four ratings below, described in the Cochrane Reviewers' Handbook ${ }^{18}$ :

- Clearly adequate: if adequate concealment reported.

- Possibly adequate: if the random allocation was mentioned but the actual method used to conceal was unclear/not known.

- Clearly inadequate: if there was mention of inadequate concealment.

- Allocation concealment not used.

2. Blinding of the outcome assessment:

- Yes

- No

- Not appropriate

3. Completeness of the follow-up (is there a clear explanation for withdrawals and dropouts in each screening group?):

- Yes

- No

- No withdrawals/dropouts

4. The proportion of participants who completed the study was recorded.

Using the four criteria listed above, each study was categorized as: low risk of bias (A), median risk of bias (B), and high risk of bias (C), according to section 6.7.1 of the Cochrane Reviewers' Handbook.

Two reviewers independently extracted data using specially designed data extraction forms. For each included study, the following data were recorded:

- year of publication, country of origin, and source of study funding,

- details of the participants including demographic characteristics and criteria for inclusion,

- details on the type of intervention and comparisons,

- details on the study design, and

- details on the outcomes reported, including method of assessment.

Authors of the included studies were asked to confirm the data extracted.

For dichotomous outcomes, the estimate of effect of an intervention was expressed as relative risks together with 95 percent confidence intervals.
Meta-analysis was attempted only if there were studies of similar comparisons that report the same outcome measures. For continuous outcomes, mean differences and 95 percent confidence intervals were used to summarize the data for each group.

Relative risks were combined for dichotomous data and weighted mean differences for continuous data. Random effects models were performed throughout. For cluster randomized trials, the patient numbers were reduced to an effective sample size as described by Hauck et al. ${ }^{19}$

Meta-regression was used to explore effects of the following factors on incidence of oral cancer or potentially malignant oral lesions: level of risk for oral cancer (low, medium, or high risk) and duration of trial. Heterogeneity was assessed by inspection of a graphical display of the estimated treatment effects from the trials along with their 95 percent confidence intervals and by Cochran's test for homogeneity undertaken prior to each meta-analysis. Sensitivity analysis was used to assess robustness of results to trial quality. Funnel plots were used to assess for evidence of bias. ${ }^{19}$

Type and frequency of side effects and adverse effects such as false positives or false negatives were tabulated and compared between different studies and designs.

\section{Results}

The search of MEDLINE via OVID (1966 to September 2002) revealed 1,389 citations. However, adding the terms of the Cochrane Collaborations sensitive search strategy for randomized controlled trials reduced this number to 427 citations. From these, 100 potentially relevant articles were selected for review. Following the review, only one study conducted in Kerala, India was selected for inclusion. ${ }^{20,21}$

Searches of EMBASE, CANCERLIT, Cochrane CCTR, Cochrane Specialist Register, and bibliographies of review articles did not reveal any further relevant studies that had not been identified by the MEDLINE search. Similarly, hand-searching for oral cancer screening in the identified journals did not identify any further studies.

Of 100 citations selected for the review, fortyeight described uncontrolled or non-experimental studies, ${ }^{11-15,22-64}$ eight were observational as either epidemiological studies or case-control studies, ${ }^{65-72}$ thirty-seven were narrative reviews or commentar- 
ies, ${ }^{10,73-108}$ four described controlled clinical trials, ${ }^{109-}$ 12 and three described randomized controlled trials. ${ }^{20,21,113}$ However, these randomized controlled trials did not examine toluidine blue, brush biopsy, or fluorescence imaging as a tool for screening or an adjunct method for screening. The only included RCT concentrated on visual screening for the detection and prevention of oral cancer. It was conducted in Kerala, India and described in three papers. ${ }^{20,21,113}$

\section{Description of the Included Study}

In the Kerala study (Trivandrum Oral Cancer Screening Study), all participants $(n=148,905)$ were apparently healthy residents aged thirty-five years or older living in thirteen clusters in rural areas of Trivandrum city, Kerala, India. Those who were bedridden, suffering from open tuberculosis or other debilitating diseases, and/or diagnosed with oral cancer were excluded from the study. In each cluster the number of eligible participants varied from 5,177 to 12,147 (mean 8,815). These clusters were allocated into an intervention cohort (number of clusters $=7$ ) and a control cohort (number of clusters $=6$ ) by blocked randomization.

The intervention group in the second round of screening consisted of 78,969 persons, 33,540 of whom were male and 45,429 female (Table 2). The participation rate for screening at least once was 88.5 percent: males 81.7 percent and females 93.6 percent. Of the screened subjects, 6.3 percent $(n=4,408)$ had a referable lesion, and 59.7 percent $(2,630)$ of the screen positive subjects complied with referral (Table 3). The control group consisted of 74,739 persons.
Trained and qualified health workers were responsible for carrying out an oral visual inspection. These health workers interviewed the eligible subjects to obtain information by using household information to identify the owner as well as special information related to social and personal habits such as paan and/or tobacco chewing, smoking, alcohol consumption, and dietary supplements. At the same time, the health workers gave advice to those with current tobacco and alcohol habits on giving them up and encouraged others to not initiate these habits.

Intraoral and extraoral examinations were performed in bright daylight with the help of a flashlight. Cervical lymph nodes were palpated. The findings were recorded as normal, nonreferable lesions and referable lesions.

The positively screened participants were examined by dentists or physicians for confirmation. For the confirmed subjects, advice was given to stop tobacco and alcohol habits. In addition, oral biopsies were performed. The intervention and control groups are being followed up. In this study, oral cancer mortality was reported as a major outcome; other outcomes (participation rate, the detection rate of oral precancer and oral cancer, compliance with referral, incidence rate of oral cancers, and characteristics of the oral cancer in the study group) were also measured. The control group clusters were also visited by a "control health worker" who recorded the same sociodemographic information and measured height, weight, blood pressure, and respiratory peak flow measurements. However, the control health workers were not trained in how to undertake a visual oral inspection.

Table 2. Comparison between the intervention and control groups

\begin{tabular}{|c|c|c|c|c|}
\hline Study & \multicolumn{2}{|c|}{ Intervention Cohort } & \multicolumn{2}{|l|}{ Control Cohort } \\
\hline Number of Interviewed Participants & \multicolumn{2}{|c|}{$\mathrm{n}=7$ clusters $(69,936)$} & \multicolumn{2}{|c|}{$\mathrm{n}=6$ clusters $(60,843)$} \\
\hline Gender & \multicolumn{2}{|l|}{$\begin{array}{l}\text { 27,391 male; } \\
42,545 \text { female }\end{array}$} & \multicolumn{2}{|l|}{$\begin{array}{l}22,933 \text { male; } \\
37,910 \text { female }\end{array}$} \\
\hline No Habits & $\begin{array}{lr}\text { male } & 7,368 \\
\text { female } 31,440\end{array}$ & $\begin{array}{l}\text { (26.9 percent); } \\
\text { (73.9 percent) }\end{array}$ & $\begin{array}{lr}\text { male } & 8,049 \\
\text { female } 31,010\end{array}$ & $\begin{array}{l}\text { (35.1 percent); } \\
\text { (81.1 percent) }\end{array}$ \\
\hline Chewing Habits & $\begin{array}{lr}\text { male } & 8,080 \\
\text { female } 10,764\end{array}$ & $\begin{array}{l}\text { (29.5 percent); } \\
\text { (25.3 percent) }\end{array}$ & $\begin{array}{ll}\text { male } & 5,710 \\
\text { female } & 6,748\end{array}$ & $\begin{array}{l}\text { (24.9 percent); } \\
\text { (17.8 percent) }\end{array}$ \\
\hline Smoking Habits & $\begin{array}{lr}\text { male } & 17,064 \\
\text { female } & 9,785\end{array}$ & $\begin{array}{l}\text { ( } 62.3 \text { percent); } \\
\text { ( } 2.3 \text { percent) }\end{array}$ & $\begin{array}{lr}\text { male } & 12,040 \\
\text { female } & 341\end{array}$ & $\begin{array}{l}\text { (52.5 percent); } \\
\text { (0.9 percent) }\end{array}$ \\
\hline Drinking Habits & $\begin{array}{lr}\text { male } & 10,271 \\
\text { female } & 85\end{array}$ & $\begin{array}{l}\text { ( } 37.5 \text { percent); } \\
\text { (0.2 percent) }\end{array}$ & $\begin{array}{lr}\text { male } & 6,971 \\
\text { female } & 38\end{array}$ & $\begin{array}{l}\text { (30.4 percent); } \\
\text { (0.1 percent) }\end{array}$ \\
\hline Participation Rate & $\begin{array}{l}\text { male } \\
\text { female }\end{array}$ & $\begin{array}{l}81.7 \text { percent; } \\
93.6 \text { percent }\end{array}$ & - & \\
\hline
\end{tabular}




\section{Table 3. Screening history}

\begin{tabular}{lccc} 
Screening History & Male & Female & Total \\
\hline Not screened & 18.4 percent $(6,166)$ & 6.4 percent $(2,907)$ & 11.5 percent $(9,073)$ \\
Screened once & 48.7 percent $(16,334)$ & 41.3 percent $(18,762)$ & 44.4 percent $(35,096)$ \\
Screened twice & 32.9 percent $(11,040)$ & 52.3 percent $(23,760)$ & 44.1 percent $(34,800)$ \\
Number of subjects with referable lesions & 8.4 percent $(2,284)$ & 5.0 percent $(2,123)$ & 6.3 percent $(4,408)$ \\
Subjects complied with referral & 56.8 percent $(1,298)$ & 62.7 percent $(1,332)$ & 59.6 percent $(2,630)$
\end{tabular}

The study commenced in October 1995, and three rounds of screening at three-year intervals were planned for the study. The first round was completed in May 1998, and the second was completed in June 2002. The principal investigator of this study has confirmed our data extraction to date (Dr. Sankaranarayanan).

\section{Methodological Quality of Included Study}

The randomization procedure was conducted using restricted block randomization. Clusters were grouped into blocks of four, and allocation to screening or non-screening group was chosen at random from the six possible combinations available to each block of four. Allocation concealment was not used in this study; this has been confirmed by the author.

In this study, the health workers reported on twenty-four baseline variables including multiple age strata, occupation, education, income, household belongings such as television, and personal habits of chewing, smoking, and drinking. The intervention and control cohorts appear to have been well matched for the stratified variable age at the baseline. However, the distribution of income, education, and household belongings varied in comparability in both study groups at the base line. The distribution of tobacco and alcohol was somewhat different between the study groups. Chewing, smoking, and drinking were greater in the intervention male group than the control group (Table 3). For females, chewing and smoking habits were greater in the intervention group than the control group. However, drinking was similar in the two groups. There were fewer participants with no tobacco or drinking habits in the intervention group for both males and females (Table 3). These differences in the baseline variables might be expected in cluster randomized studies.

Blinding of the outcome assessment was not described in this study. However, because of the na- ture of the study and the outcomes assessed, it was impossible for some outcomes to be assessed blindly.

Withdrawals and dropouts were not described clearly in this study. The compliance rate in the male group with referable lesions for confirmatory examination by dentists or physicians was 49 percent as opposed to 54.7 percent among the female group at the end of the first round of screening. However, the compliance rate in the second round slightly improved. It was 59.7 percent of all individuals who screened positive, with males at 56.8 percent and females 62.7 percent. Follow-up is still going on to record the results of the screening during the next three years.

The study reported data on oral cancer incidence, disease-specific mortality, and stage at diagnosis after six years' follow-up. Data on quality of life, all cause mortality, and costs were not reported.

Among the 69,896 participants screened in the intervention group, 4,408 (6.3 percent) were found to have referable lesions. Of these, 2,630 (59.7 percent) complied with referral for confirmatory examination. The number of oral precancerous lesions was 1,887 (71.75 percent) and oral cancer 100 (3.8 percent). The detection rates of oral precancerous lesions and oral cancer were 27.0/1000 and 1.4/1000 screened subjects respectively. Examination of the Trivandrum cancer registry recorded 255 patients with oral cancer. One hundred and forty-nine patients were in the intervention group and 106 in the control group. The crude incident rate of oral cancer was $43.3 / 100,000$ pyrs (person-years) in the intervention cohort and 32.2/100,000 pyrs in the control group (Table 4).

There was no statistically significant difference in death rate from oral cancer between the intervention group and control. Over the six-year period, sixty-five of 149 subjects with oral cancer in the intervention group and sixty-two of the 106 cases in the control group died, a six-year case fatality of 43.6 percent and 58.5 percent in the respective groups. 


\begin{tabular}{lll}
$\begin{array}{l}\text { Table 4. Number of oral cancers diagnosed and death associated rate } \\
\text { Kerala Project }\end{array}$ & Intervention Group & Control Group \\
\hline Number of oral cancers & 149 (male 83, female 66) & 106 (male 64, female 42) \\
Oral cancer deaths & 65 & 62 \\
Total number of participants & 78,969 & 74,739 \\
Crude incidence rate of oral cancer & $43.3 / 100,000$ person-years & $32.2 / 100,000$ person-years \\
Case-fatality rate & 43.6 percent & 58.5 percent \\
Age-standardized oral cancer mortality rate & $21.2 / 100,000$ person-years & $21.3 / 100,000$ person-years \\
Crude death rate from oral cancer & $18.9 / 100,000$ person-years & $18.8 / 100,000$ person-years
\end{tabular}

The age-standardized mortality rate associated with oral cancer in the intervention group and control group were $21.2 / 100,000$ pyrs and 21.3/100,000 pyrs respectively (Table 4 ).

We examined survival by comparing the proportion of patients alive three years after diagnosis. The three-year survival rate was 57.5 percent in the intervention group and 38.8 percent in the control group ( $\mathrm{p}>0.05$ ).

The stage distribution of oral cancer cases based on the International Union Against Cancer/ American Joint Committee on Cancer (UICC/AJCC) clinical TNM stage was reported. In the intervention group, 37.6 percent of the cases were in stage I or II, as opposed to 18.9 percent of cases in the control group $(\mathrm{p}<0.001)$. On the other hand, 57.5 percent of cases in the control group were in the stage III or IV versus 42.3 percent of cases in the intervention group. Unknown stage cases were 20.1 percent in the intervention group and 23.6 percent in the control group.

In this study, compliance with scheduled screening averaged 81.6 percent for males and 93.6 percent for females in the intervention group, whereas the overall participation rate was 81.4 percent in the control group.

The program's sensitivity and specificity in detecting oral cancer were 81.5 percent and 84.8 percent respectively. The positive predictive value of prevalence screening for this study was calculated as the number of screen-selected oral cancers as a proportion of total screen positive subjects (confirmed by biopsy), and it was 39.6 percent for oral cancer.

\section{Discussion}

Considering the increased rate of oral cancer incidence globally, ${ }^{5}$ the need to decrease the burden of suffering from oral cancer is crucial. The oral cavity is easily accessible for physical examination. ${ }^{8}$ Many attempts have been made to assess the effectiveness of oral cancer screening in decreasing the mortality associated with oral cancer. ${ }^{47,54}$ Different methods have been used to accomplish screening. ${ }^{14,46,62}$ Unfortunately, most of the studies reporting on screening strategies have been uncontrolled and thus are not included in the present review.

This is the first systematic review of screening strategies on oral cancer reported in the literature based on randomized controlled trials only. However other reviews of effectiveness ${ }^{86,97}$ and test performance ${ }^{92}$ have also been undertaken.

The Canadian task force on preventive health care conducted a review study on the prevention of oral cancer mortality ${ }^{86}$ Although the review was systematic, no clear indication of the review methodology was described. Moreover, case-control and cohort studies were included in this review without employing clear inclusion and exclusion criteria. This review focused only on visual clinical examination as a mode for screening without mentioning any details of other types of oral screening strategies. The results of their review suggest that for population screening there is fair evidence to specifically exclude screening for oral cancer. For opportunistic screening (high-risk groups could be targeted) during periodic examination, however, there is insufficient evidence to recommend inclusion or exclusion of screening for oral cancer.

A meta-analysis with regard to the test performance of visual examination as a screening method has previously been performed, but this was not undertaken as part of the systematic review. ${ }^{92}$ Clear criteria for inclusion and exclusion were applied. However, the included studies varied in both their study design and circumstances with regard to screening strategy used, population sample, prevalence of dis- 
ease in those populations, and personnel undertaking screening and their experience as well as training in performing the screening. The results of this meta-analysis suggest that, although the included studies have considerable heterogeneity, visual screening had a high discriminatory ability to pick up the target disease, especially as the derived sensitivity values ranged from 0.60 to 0.95 and the specificity figures were between 0.94 and 0.99 for most studies conducted around the world.

The Department of Public Health and Epidemiology in the University of Birmingham (UK) conducted a review using toluidine blue method for screening. ${ }^{85}$ This study systematically reviewed the literature on the usefulness of toluidine blue dye as a screening tool for the detection of oral cancer in general dental practice. The results of this review showed that there is no evidence to suggest that toluidine blue was a cost-effective method of picking up oral cancers in a primary care setting. A meta-analysis study was conducted to evaluate the efficacy of screening for oral cancer with toluidine blue. ${ }^{97}$ However, no inclusion and exclusion criteria for the studies reviewed were reported.

The study identified in this review was found to have some methodological weaknesses, some of which are discussed in the article. ${ }^{21}$ First, the main advantage of RCTs is that random allocation to groups allows both known and unknown confounding factors to be distributed evenly. The included study used cluster randomization with panchyaths (municipal administrative units in rural areas in India) as the unit of allocation. When relatively few clusters are randomized, the chance of unbalances in baseline characteristics is increased, and such unbalances were apparent in the study. The Kerala project showed that personal habits with regard to drinking, smoking, and paan chewing were greater in the intervention group than in the control. These differences could bias the results as it may be expected there would be a greater incidence of oral cancer in the group with a higher level of smoking/ drinking/paan chewing. The authors of the study suggest the possibility of information bias: participants in the intervention group were more forthcoming in reporting their habits because they were being offered screening. In addition to that, there was no clear explanation of dropouts in each treatment group. Furthermore, the low compliance rate of the positive screened subjects (59.7 percent) might affect the validity of the study.
This study did not raise any issues with regard to costs, quality of life, or even the harms of screening from false positive or false negative findings. These factors may influence the results positively or negatively and are important issues to consider when implementing the screening programmes.

Speight et al. ${ }^{102}$ reviewed the psychological disadvantages of screening - namely, risks of increased levels of anxiety in individual patients, trauma from a false positive result, distress of a true positive result, and unnecessary investigations. These could be reduced by careful and honest dissemination of information and by educating subjects about risk reduction benefits.

The incidence of oral cancer and potentially premalignant oral lesions, the stage at diagnosis, and specific death mortality for at least three years were clearly described. These reported data provided positive value for this study. Nevertheless, the results of the included study showed that there was no reduction in incidence of or mortality from oral cancer after the introduction of the screening program and the improvement in survival rates with early stage oral cancer were due to lead time and length bias. When evaluating the effectiveness of the early detection and treatment of a condition, the lead time must be subtracted from the overall survival time of screened patients to avoid lead time bias. Otherwise, early detection merely increases the duration of the patients' awareness of their disease without reducing their mortality or morbidity. Numerous cancerscreening procedures were thought to improve survival until lead time bias was addressed. ${ }^{114}$

Although the Kerala study showed that the sensitivity and specificity of visual examination to detect oral lesions were over 80 percent and similar to other studies, ${ }^{40,61}$ there was no difference in oral cancer mortality after six years of follow-up. This may be explained by a lack in understanding of the natural history of oral cancer and of the effectiveness of treatment. The UK National Screening Committee undertook an assessment of oral cancer screening during 2002-03. The conclusions of the expert group as presented to the committee were: "There is an overwhelming need for more information about the epidemiology and natural history of oral cancer. Greater awareness of the disease amongst all health professionals and standardised referral pathways would facilitate earlier institution of treatment when necessary. The population should be aware of the disease including possible risk factors and early signs 
and symptoms." 115 Thus the need to understand the natural history of oral cancer is crucial.

For diagnostic screening, randomized controlled trials are required to provide the most reliable information for decisions in clinical practice. The lack of trials in this field might be attributed to the many possible obstacles, including the duration of follow-up required, the reproducibility of the screening test by the health workers, compliance, cost, and the relatively low incidence of oral cancer in certain countries.

Unfortunately, there are no published randomized controlled trials of brush biopsy, fluorescence imaging, and toluidine blue. Many clinical trials and reports have raised optimistic indications for the prospective role of these methods as adjunctive aids in the early detection of oral cancer, ${ }^{50,64,75}$ but the vast majority of these studies concentrated on the test diagnostic characteristics rather than the use of these tests for screening.

\section{Conclusions}

Our results suggest that there is insufficient evidence to recommend inclusion or exclusion of screening for oral cancer using a visual examination in the general population. In addition, there is no evidence for other methods of screening, such as toluidine blue, fluorescence imaging, and brush biopsy, to be either included or excluded. The data need to be supplemented by further randomized controlled trials to provide the highest level of evidence for practice. However, systematic examination of the oral cavity by general dental practitioners or physicians should remain an integral part of their routine daily work. Particular attention should be paid to high-risk individuals.

Given the lack of evidence to support or refute the use of screening programs for oral cancer, further studies using high-quality methodology on the natural history of oral cancer and prevention methods as well as the effectiveness of opportunistic screening in high risk groups are required. Most recently, many studies have suggested that molecular markers could be useful as prognostic and predictive markers for the premalignant oral lesion. ${ }^{116}$ It is feasible that research in this field may open doors for better understanding and prognostication. The identification of genes involved in oral cancer is an essential prerequisite to the development of molecular markers for screening.

\section{Acknowledgments}

We wish to thank Emma Tavendar and Luisa Fernandez (Cochrane Oral Health Group) for their help with preparing this review; Sylvia Bickley (Cochrane Oral Health Group) for her assistance with literature searching; and Professor Helen Worthington for her assistance with developing this review. We are grateful to Dr Sankaranarayanan for sharing his prepublication data with the reviewers.

\section{REFERENCES}

1. The international statistical classification of diseases and related health problems. 10th revision, vol. 1. Geneva: World Health Organization, 1992.

2. Jemal A, Murray T, Samuels A, Ghafoor A, Ward E, Thun M. Cancer statistics 2003. CA Cancer J Clin 2003;53(1): 5-26.

3. Cancer Statistics Registrations. Registrations of cancer diagnosed in 1999. London: Office for National Statistics, 2002.

4. Greenlee RT, Hill-Harmon MB, Murray T, Thun M. Cancer statistics 2001. CA Cancer J Clin 2001;51:15-36.

5. Ferlay J, Bray F, Pisani P, Parkin DM. GLOBOCAN 2000 , cancer incidence, mortality and prevalence worldwide, Version 1.0. Lyon: IARC Press, 2001.

6. Dolan RW, Vaughan CW, Fuleihan N. Symptoms in early head and neck cancer: an inadequate indicator. Otolaryngol Head Neck Surg 1998;118:463.

7. Ellison MD, Campbell BH. Screening for cancer of the head and neck: addressing the problem. Surg Oncol Clin N Am 1999;8:725-34.

8. Chiodo GT, Eigner T, Rosenstein DI. Oral cancer detection, the importance of routine screening for prolongation of survival. Postgrad Med 1986;80:231-6.

9. Sankila R, Coll EC. Evaluation and monitoring of screening program. Luxembourg: Office for the Official Publication of the European Communities, 2001

10. Zakzerwska JM, Hindle I, Speight PM. Practical considerations for the establishment of an oral cancer screening programme. Community Dent Health 1993;10(Suppl 1):79-85.

11. Eliezri YD. The toluidine blue test: an aid in the diagnosis and treatment of early squamous cell carcinomas of mucous membranes. J Am Acad Dermatol 1988; 18:1339-49.

12. Moyer GN, Taybos GM, Pelleu GB. Toluidine blue rinse: potential for benign lesions in early detection of oral neoplasms. J Oral Med 1986;41:111-3.

13. Onofre MA, Sposto MR, Navarro CM. Reliability of toluidine application in the detection of oral epithelial dysplasia and in situ and invasive squamous cell carcinomas. Oral Surg Oral Med Oral Pathol Oral Radiol Endod 2001;91:535-40.

14. Christian DC. Computer-assisted analysis of oral brush biopsies at an oral cancer screening program. J Am Dent Assoc 2002; 133:357-62. 
15. Onizawa K, Saginoya H, Furuya Y, Yoshida H. Fluorescence photography as a diagnostic method for oral cancer. Cancer Lett 1996;108:61-6.

16. Mulrow CD. Rationale for systematic reviews. BMJ 1994;309:597-9.

17. Mulrow CD. The medical review article: state of the science. Ann Intern Med 1987;106:485-8.

18. Clarke M, Oxman AD. Cochrane reviewers' handbook 4.1.6. The Cochrane Library. Oxford: Update Software, 2003 (updated quarterly).

19. Hauck WW, Gilliss CL, Donner A, Gortner S. Randomisation by cluster. Nurs Res 1991;40(6):356-8.

20. Sankaranarayanan R, Mathew B, Thomas T, Pisani P, Pandey M, Ramadas K, et al. Early finding from a community-based, cluster-randomised, controlled oral cancer screening trial in Kerala, India. Cancer 2000; 88:664-73.

21. Ramadas K, Sankaranarayanan R, Jacob B, Thomas G, Somanathan $\mathrm{T}$, Mahe $\mathrm{C}$, et al. Interim results from a cluster randomised controlled oral cancer screening trial in Kerala, India. Oral Oncol 2003;39:580-8.

22. Banoczy J, Rigo O. Prevalence study of oral precancerous lesions within a complex screening system in Hungary. Community Dent Oral Epidemiol 1991;19:265-7.

23. Betz CS, Stepp H, Janda P, Arbogast S, Grevers G, Baumgartner R, et al. A comparative study of normal inspection, autofluorescence and 5-ala-induced PPIX fluorescence for oral cancer diagnosis. Int J Cancer 2002;97:245-52.

24. Bouquot JE, Gorlin RJ. Leukoplakia, lichen planus, and other oral keratoses in 23,616 white Americans over the age of 35 years. Oral Surg Oral Med Oral Pathol Oral Radiol Endod 1986;61:373-81.

25. Burzniski NT, Firriolo FJ, Butters JM, Sorrell CL. Evaluation of oral cancer screening. J Cancer Educ 1997;12: 95-9.

26. Dombi C, Vorose-Balog T, Czegledy A, Hermann P, Vincze N, Banoczy J. Risk group assessment of oral precancer attached to X-ray lung-screening examinations. Community Dent Oral Epidemiol 2001;29:9-13.

27. Downer MC, Evans AW, Hallett CM, Jullien JA, Speight PM, Zakrzewska JM. Evaluation of screening for oral cancer and precancer in a company headquarters. Community Dent Oral Epidemiol 1995;23:84-8.

28. Downer MC, Jullien JA, Speight PM. An interim determination of health gain from oral cancer and precancer: 1. obtaining health state utilities. Community Dent Health 1997;14:139-42.

29. Downer MC, Jullien JA, Speight PM. An interim determination of health gain from oral cancer and precancer screening: 3. preselecting high risk individuals. Community Dent Health 1998;15:72-6.

30. Epstein JB, Scully C, Spinelli JJ. Toluidine blue and Lugol's iodine application in the assessment of oral malignant disease and lesions at risk of malignancy. J Oral Pathol Med 1992;21:160-3.

31. Epstein JB, Oakley C, Millner A, Emerton S, van der Meij E, Le N. The utility of toluidine blue application as a diagnostic aid in patients previously treated for upper oropharyngeal carcinoma. Oral Surg Oral Med Oral Pathol Oral Radiol Endod 1997;83:537-47.
32. Field EA, Morrison T, Darling AE, Parr TA, Zakrzewska JM. Oral mucosal screening as an integral part of routine dental care. Br Dent J 1995;179:262-6.

33. Garrote LF, Sankaranarayanan R, Lence Anta JJ, Sava AR, Parkin DM. An evaluation of the oral cancer control program in Cuba. Epidemiol 1995;6:428-31.

34. Hand JS, Whitehill M. The prevalence of oral mucosal lesions in an elderly population. J Am Dent Assoc 1986;112:73-6.

35. Handlers JP. Diagnosis and management of oral softtissue lesions: the use of biopsy, toluidine blue staining, and brush biopsy. J Can Dent Assoc 2001;29:602-6.

36. Ikeda N, Ishii T, Iida S, Kawai T. Epidemiological study of oral leukoplakia based on mass screening for oral mucosal diseases in a selected Japanese population. Community Dent Oral Epidemiol 1991;19:160-3.

37. Ikeda N, Downer MC, Ishii T, Fukano H, Nagao T, Inoue $\mathrm{K}$. Annual screening for oral cancer and precancer by invitation to 60-year-old residents of a city in Japan. Community Dent Health 1995;12:133-7.

38. Ikeda N, Handa Y, Khim SP, Durward C, Axell T, Mizuno $\mathrm{H}$, et al. Prevalence study of oral mucosal lesions in a selected Cambodian population. Community Dent Oral Epidemiol 1995;23:49-54.

39. Jullien JA, Zakrzewska JM, Downer MC, Speight PM. Attendence and compliance at an oral cancer screening programme in a general medical practice. Oral Oncol 1995;31(B):202-6.

40. Jullien JA, Downer MC, Speight PM, Zakrzewska JM. Evaluation of health care workers' accuracy in recognising oral cancer and precancer. Int Dent $\mathrm{J}$ 1996;46:334-9.

41. Jullien JA, Downer MC, Zakrzewska JM, Speight PM. Evaluation of a screening test for the early detection of oral cancer and precancer. Community Dent Health 1995; 12:3-7.

42. Leunig A, Mehlmann M, Betz C, Stepp H, Arbogast S, Grevers G, Baumgartner R. Fluorescence staining of oral cancer using a topical application of 5-aminolevlinic acid, fluorescence microscopic studies. J Photochem Photobiol B 2001;60:44-9.

43. Martin IC, Kerawala CJ, Reed M. The application of toluidine blue as a diagnostic adjunct in the detection of epithelial dysplasia. Oral Surg Oral Med Oral Pathol Oral Radiol Endod 1998;85:444-6.

44. Mashberg A. Reevaluation of toluidine blue application as a diagnostic adjunct in the detection of asymptomatic oral squamous carcinoma. Cancer 1980;46:758-63.

45. Mashberg A. Tolonium (toluidine blue) rinse-A rinse screening method for recognition of squamous carcinoma. JAMA 1981;245:2408-10.

46. Miller RL, Simms BW, Gould AR. Toluidine blue staining for detection of oral premalignant lesions and carcinomas. J Oral Pathol 1988;17:73-8.

47. Nagao T, Warnakulasuriya S, Ikeda N, Fukano H, Fujiwara K, Miyazaki H. Oral cancer screening as an integral part of general health screening in Tokoname City, Japan. J Med Screen 2000;7:203-8.

48. Nagao T, Ikeda N, Fukano H, Miyazaki H, Yano M, Warnakulasuriya S. Outcome following a population screening programme for oral cancer and precancer in Japan. Oral Oncol 2000;36:340-6. 
49. Niebel HH. In vivo staining for delineation of oral intraepithelial neoplastic change: preliminary report. J Am Dent Assoc 1964;68:801-6.

50. Onizawa K, Okamura N, Saginoya H, Yusa H, Yanagawa T, Yoshida H. Analysis of fluorescence in oral squamous cell carcinoma. Oral Oncol 2002;38:343-8.

51. Pandey M, Thomas G, Somanathan T, Sankaranarayanan R, Abraham EK, Jacob BJ, et al. Evaluation of surgical excision of non-homogeneous oral leukoplakia in a screening intervention trial, Kerla, India. Oral Oncol 2001;37:103-9.

52. Pindborg JJ, Daftary DK, Mehta FS. A follow-up study of sixty-one oral dysplastic precancerous lesions in Indian villagers. Oral Surg 1977;43:383-90.

53. Rosen S, Cornish M, Edelson J. Detection of early oral cancer by toluidine blue. J Can Dent Assoc 1971;37: 347-9.

54. Santana JC, Delgade L, Miranda J, Sanchez M. Oral cancer case finding program (OCCFP). Oral Oncol 1997;33:10-2.

55. Scherubl H, von Lampe B, Faiss S, Daubler P, Bohlmann $\mathrm{P}$, Plath T, et al. Screening for oseophageal neoplasia in patients with head and neck cancer. Br J Cancer 2002;86:239-43.

56. Seoane J, Gonzalez-Reforma N, Aguado A, Romero MA, Varela-Centelles PI. Assessment of dental students' diagnostic accuracy for oral cancer screening. J Dent Educ1997;61:437-9.

57. Silverman S, Migliorati C, Barbosa J. Toluidine blue staining in the detection of oral precancerous and malignant lesions. Oral Surg 1984;57:379-82.

58. Speight PM, Elliott AE, Jullien JA, Downer MC, Zakzerwska JM. The use of artificial intelligence to identify people at risk of oral cancer and precancer. Br Dent J 1995;179:382-7.

59. Vahidy NA, Zaidi SHM, Jafarey NA. Toluidine blue test for detection of carcinoma of the oral cavity: an evaluation study. J Surg Oncol 1972;17:434-8.

60. Warnakulasuriya S, Ekanayake A, Stjernsward J, Pindborg JJ, Sivayoham S. Compliance following referral in the early detection of oral cancer and precancer in Sri Lanka. Community Dent Oral Epidemiol 1988;16:326-9.

61. Warnakulasuriya S, Pindborg JJ. Reliability of oral precancer screening by primary health care workers in Sri Lanka. Community Dent Health 1990;7:73-9.

62. Warnakulasuriya S, Nanayakkara BG. Reproducibility of an oral cancer and precancer detection program using a primary health care model in Sri Lanka. Cancer Detect Prev 1991;15:331-4.

63. Warnakulasuriya S, Johnson NW. Sensitivity and specifity of OraScan toulidine blue mouthrinse in the detection of oral cancer and precancer. J Oral Pathol Med 1996;25:97-103.

64. Sciubba JJ. Improving detection of precancerous and cancerous oral lesions: computer-assisted analysis of the oral brush biopsy. J Am Dent Assoc 1999;130:1445-57.

65. Axell T. Occurrence of leukoplakia and some other oral white lesions among 20,333 adult Swedish people. Community Dent Oral Epidemiol 1987;15:46-51.
66. Bouquot JE. Common oral lesions found during a mass screening examination. J Am Dent Assoc 1986;112:50-7.

67. Hogewind WFC, van der Waal I. Prevalence study of oral leukoplakia in a selected population of 1000 patients from the Netherlands. Community Dent Oral Epidemiol 1988;16:302-5.

68. Ikeda N, Downer MC, Ozowa Y, Inoue C, Mizuno T, Kawai T. Characteristics of participants and non-participants in annual mass screening for oral cancer in 60year-old residents of Tokoname City, Japan. Community Dent Health 1995;12:83-8.

69. Lu CT, Ho CS, Ko YC, Hsieh CC, Lan SJ. A case-control study of oral cancer in Changhua County, Taiwan. J Oral Pathol Med 1996;25:245-8.

70. Malaowalla AM, Silverman S, Mani NJ, Bilimoria KF, Smith LW. Oral cancer in 57,518 industrial workers of Gujarat, India. Cancer 1976;37:1882-6.

71. Nandakumar A, Thimmasetty KT, Sreeramareddy NM, Venugopal TC, Rajanna Vinutha AT, et al. A populationbased case-control investigation on cancers of the oral cavity in Bangalore, India. Br J Cancer 1990;62:847-51.

72. Sankaranarayanan R, Garrote FL, Anata JL, Pisani P, Rodriguez AS. Visual inspection in oral cancer screening in Cuba: a case-control study. Oral Oncol 2002;38:131-6

73. Allen CM. Toluidine blue: proceed with caution? Oral Surg Oral Med Oral Pathol Oral Radiol Endod 1998;86:255.

74. Oral cancer guidelines for early detection. London: British Dental Association, 1998

75. Opportunistic oral cancer screening: a management strategy for dental practice. London: British Dental Association, 2000.

76. Boyle P, Macfarlane GJ, Blot WJ, Chiesa F, Lefebvre JL, Mano Azul A, et al. European School of Oncology advisory report to the European Commission for the Europe Against Cancer Programme: oral carcinogenesis in Europe. Oral Oncol 1995;31(B):75-85.

77. Calabrese L, Tradati N, Nickolas TN, Giugliano G, Zurrida S, Scully C, et al. Cancer screening in otorhinolaryngology. Oral Oncol 1998;34:1-4.

78. Chamberlain J. Evaluation of screening for cancer. Community Dent Health 1993;10(Suppl 1):5-11.

79. Downer MC, Speight PM. Cost and value considerations in screening for oral cancer and precancer. Community Dent Health 1993;10(Suppl 1):71-8.

80. Drinnan AJ. Screening for oral cancer and precancer: a valuable new technique. Gen Dent 2000:656-60.

81. Ellison MD, Campbell BH. Screening for cancer of the head and neck: addressing the problem. Surg Oncol Clin N Am 1999;8:725-34.

82. Oral cancer series: practical prevention. Ferney-Voltaire, France: FDI World Dental Federation, 1997.

83. Diagnosis oral cancer: can toluidine blue mouthwash help? Ferney-Voltaire, France: FDI World Dental Federation, 1998.

84. Franceschi S, Barzan L, Talamini R. Screening for cancer of the head and neck: if not now, when? Oral Oncol 1997;33:313-6.

85. The effectiveness of toluidine blue dye as adjunct to oral cancer screening in general dental practice. Birmingham: 
University of Birmingham, Department of Public Health and Epidemiology, 2000.

86. Hawkins RJ, Wang EL, Leake JL. Preventive health care, 1999 update: prevention of oral cancer mortality. J Can Dent Assoc 1999;65:617-27.

87. Horowitz AM. Perform a death-defying act: the 90 -second oral cancer examination. J Am Dent Assoc 2001;132:36S-40S

88. Lund AE. Do you routinely screen your patients for oral cancer? J Am Dent Assoc 1999;130:1699.

89. Marder MZ. Ask the expert: what are the diagnostic protocols for oral cancer screenings? J Am Dent Assoc 2001;132:83-4.

90. Prevention and controlling oral and pharyngeal cancer recommendations from a national strategic planning conference. MMWR recommendations and reports 1998;47(RR14):1-11.

91. Promting oral health, intervention for preventing dental caries, oral and pharyngeal cancers, and sports-related craniofacial injuries. MMWR recommendations and reports 2001;50(RR21):1-13.

92. Moles DR, Downer MC, Speight PM. Meta-analysis of measures of performance reported in oral cancer and precancer screening studies. Br Dent J 2002;192:340-4.

93. Ogden GR, Cowpe JG, Chisholm D. Cost of oral screening. Lancet 1991;337:920-1.

94. Pemberton MN, Sloan P, Thakker N. Oral cancer screening. Br Dent J 2000;189:469.

95. Richards D, Lawrence A. Oral cancer screening. Br Dent J 2000;189:468.

96. Rodrigues VC, Moss SM, Tuomainen H. Oral cancer in the UK: to screen or not to screen. Oral Oncol 1998;34:454-65.

97. Rosenberg D, Cretin S. Use of meta-analysis to evaluate tolonium chloride in oral cancer screening. Oral Surg Oral Med Oral Pathol Oral Radiol Endod 1989;67:621-7.

98. Sankaranarayanan R. Health care auxiliaries in the detection and prevention of oral cancer. Oral Oncol 1997;33:149-54.

99. Scully C. Clinical diagnostic methods for the detection of premalignant and early malignant oral lesions. Community Dent Health 1993;10(Suppl 1):43-52.

100. Silverman S. Early diagnosis of oral cancer. Cancer 1988;62:1796-9.

101. Smart CR. Screening for cancer of the aerodigestive tract. Cancer 1993;72:1061-5.

102. Speight PM, Zakzerwska J, Downer MC. Screening for oral cancer and precancer. Oral Oncol 1992;28(B):45-8.
103. Speight PM, Hammond P. The use of machine learning in screening for oral cancer: artificial neural networks in cancer diagnosis, prognosis and patient management. London: CRC Press, 1998:1-17.

104. UK working group on screening for oral cancer and precancer: conclusions and recommendations. Community Dent Health 1993;10(Suppl 1):87-9.

105. Warnakulasuriya S, Johnson NW. Strength and weaknesses of screening programmes for oral malignancies and potentially malignant lesions. Eur J Cancer Prev 1996;5:93-8.

106. Warnakulasuriya S. Performance measurement of oral cancer and pre-cancer screening studies. Br Dent J 2002;192:332.

107. Zakrzewska JM, Martin IC. Oral cancer screening. Br Dent J 2000;189:124-5.

108. Porter SR, Scully C. Early detection of oral cancer in the practice. Br Dent J 1998;185:72-3.

109. Downer MC, Jullien JA, Speight PM. An interim determination of health gain from oral cancer and precancer screening: 2. developing a model of population screening. Community Dent Health 1997;14:227-32.

110. Gupta PC, Pindborg JJ, Bhonsle RB, Murti PR, Mehta $\mathrm{FS}$, Aghi MB, et al. Intervention study for primary prevention of oral cancer among 36,000 Indian tobacco users. Lancet 1986:1235-9.

111. Gupta PC, Mehta FS, Pindborg JJ, Bhosle RB, Daftary DK, Aghi MB. Primary prevention trial of oral cancer in India: a 10-year follow-up study. J Oral Pathol Med 1992;21:433-9.

112. Mathew B, Sankaranarayanan R, Wesley R, Joseph A, Krishnan NM. Evaluation of utilisation of health workers for secondary prevention of oral cancer in Kerala, India. Oral Oncol 1995;31B:193-6.

113. Mathew B, Sankaranarayanan R, Sunilkumar KB, Kuruvila B, Pisani P, Krishnan NM. Reproducibility and validity of oral visual inspection by trained health workers in the detection of oral precancer and cancer. $\mathrm{Br} \mathrm{J}$ Cancer 1997;76:390-4.

114. Morrison AS. The effects of early treatment, lead time, and length bias on the mortality experienced by cases detected by screening. Int J Epidemiol 1982;11(3):261-7.

115. UK National Screening Committee. At: www.nsc.nhs.uk. Accessed: March 13, 2003.

116. Thakker NS, Sloan P. Newer aids in oral cancer screening. In: Pandey M, ed. Recent advances in oncology, vol. 2. New Delhi, India: Jaypee Brothers Medical Publishers, 2002:65-85. 